\title{
Sexual initiation and associated factors among young women in West Shoa, Ambo Town, Ethiopia: a community-based cross-sectional study
}

\author{
Digafe Tsegaye Nigatu $^{1 *}$ D, Asefa Seme ${ }^{2}$, Shewaye Fituma ${ }^{1}$ and Mesfin Tafa Segni ${ }^{3}$
}

\begin{abstract}
Background: For physiological as well as behavioral reasons, sexual debut increases young individuals' risk for infection with sexually transmitted infection including HIV. It is fundamental to recognize the factors related to sexual debut in a broader context for designing and implementing effective interventions targeting youth.

Methods: Community-based cross-sectional study was employed from January to May, 2013 among females of Ambo town. A multistage sampling technique was applied. The participants were selected using simple random sampling technique. Face to face interview using structured and pretested questionnaires were used to collect thedata from the study participants. Bivariate and multivariate logistic regression analysis was used to determine the predictors of sexual initiation.

Results: Three hundred seventeen (49.9\%) of the respondents have ever had sex. The mean age at first sexual initiation was 16.6 (SD \pm 2.3 ) years. Being in age group 20-24 [Adjusted Odds Ratio (AOR) \& $(95 \% \mathrm{Cl})=2.75(1.74,4.34)$ ], Educational level [AOR\& $(95 \% \mathrm{Cl})=0.20(0.08,0.48)]$, being in school [AOR\& $(95 \% \mathrm{Cl})=0.19(0.11,0.33)]$, having paid job $[$ AOR\& $(95 \% \mathrm{Cl})=2.20(1.19,4.07)]$, peer pressure [AOR\& $(95 \% \mathrm{Cl})=3.20(2.08,4.94)]$, alcohol consumption $[$ AOR\& $(95 \% \mathrm{Cl})=2.17(1.43,3.28)]$, and pornographic materials $[\mathrm{AOR} \&(95 \% \mathrm{Cl})=2.27(1.43,3.61)]$ had significant association with sexual initiation.

Conclusion: Substantial numbers of females had started sexual activity that might expose them to different reproductive health problems. In general age group, peer pressure, alcohol consumption and watching pornographic materials were found to be predictors for the sexual debut. Therefore, building life skills, establishing youth friendly clubs should be intensified.
\end{abstract}

\section{Background}

According to World Health Organization (WHO), youth is defined as an individual aged 15 to 24 years while adolescents are those aged 10 to 19 years and young people as those between the ages of 10 to 24 years old. Adolescence is a period of opportunity and risk when numerous young people practice critical and life-defining experiments such as their first sexual experience, marriage, pregnancy, and parenthood [1].

\footnotetext{
*Correspondence: digts1@gmail.com

'Department of Public Health, College of Medicine \& Health Sciences, Ambo University, Ambo, Ethiopia

Full list of author information is available at the end of the article
}

Worldwide, the youths aged 15 to 24 estimated for more than 1 billion people and the majority live in developing countries [2]. Youth represent slightly more than $20 \%$ of Africa's population.

In sub-Saharan Africa, coitalactivity is not a new phenomenon. In recent, maturity occurs at earlier age, and the time for marriage is increased; due to this fact the practice of sexual activity occur before marriage. Sexual debut increases youths' risk for infection with numerous reproductive health issues including sexually transmitted infection and HIV [3, 4].

Ethiopia is one of the most fascinating countries in sub-Saharan Africa where there are diverse cultures, traditions, social values and practices that has impact on 
the sexual debut. Consequently, they become victims of reproductive health problems $[5,6]$.

Different literatures have demonstrated that the time of sexual initiation among female youths affected by socio-demographic factors and other factors such as pornographic materials, Khat and alcohol [7, 8]. Due to these effects, a substantial proportion of young people are engaged into sexual practice prematurely.

So far conducted studies demonstrated that the proportion of premarital sexual activity among 15-24 years young people in Oromia region was 31\%, which is significantly higher than the national average (19\%). However, factors that influence sexual initiation in Oromia youths have not yet been studied in detail [9].

Due to biological and cultural factors, girls are at a much greater risk at early ages than boys. In Ethiopia, young girls are more vulnerable to HIV than boys because of early age at sexual debut, early marriage, sexual abuse and violence such as rape and abduction [10]. Therefore, this study has been intended to determine the proportion of age at first sex and factors associated with sexual initiation among girls in the Ambo town.

\section{Methods}

\section{Study design and study setting}

Community-based cross-sectional study design was conducted among females in Ambo town from Jan. to May, 2013. Ambo town is the capital of West Shewa Zone, in Oromia regional state. The town located $114 \mathrm{~km}$ west of Addis Ababa and it has three kebeles. According to the town municipality, more than 67,514 populations live in the town in 2009 (2001 E.C) including the population of expansion areas; of which males accounts for 34,276 (50.8\%) and females 33,238 (49.2\%).

\section{Study participants \& sample size calculation}

The respondents were all female youths in the age group of 15 to 24, who lawfully reside in the town at the time of the survey. The sample size was considered by assuming a 95\% level of confidence interval, 0.05 margins of error, and with expected prevalence of sexual initiation among female youths 51\% [2]. Finally, by considering a design effect of 1.5 and $10 \%$ of non-response rate, the final sample size was 675 .

\section{Sampling procedure}

Finally, 675 respondents took part in the study. A multistage sampling procedure was employed. The town has three kebeles and two kebeles were selected by a lottery method. We then further subdivided these kebeles by Got (i.e village). From each Got/village, households were selected by simple random sampling, based on proportional allocation of the size of households in each Got or village and using the number of household as a sampling frame. The first households were selected from the town using the town's house number registration by lottery method. In cases of selected household with more than one eligible study subject, only a single respondent was chosen by random method. In cases where no eligible respondent found in the chosen household, the data collectors have gone to the next household until they found an eligible subject.

\section{Data collection \& analysis}

We adopted the questionnaire from Ethiopian Demographic Health Survey (EDHS) 2011 [6]. The questionnaire was used to elicit data from subjects on socio-demographic variables, sexual history, peer pressure, alcohol use, viewing pornographic materials which were independent variables in this study. The standardized questionnaire was first prepared in English. It was translated to Amharic and back to English again in order to maintain the validity of the instrument. Nine data collectors and one supervisor who were midwifery students from Ambo University, department of Midwifery were recruited. Data collectors and supervisors were trained for 1 day, before the pretest had been undertaken. To ensure the completeness and consistency of the collected data, supervisor and principal investigator had closely followed. Face to face interview using structured and pretested tool was used.

Epi Info Version 3.5.1 software was used to enter data. Then exported and analyzed using SPSS version 16.00. Descriptive statistical analysis with standard deviation was employed. To examine the potential predictors of sexual debut, bivariate and multivariate analysis was used. Variables which demonstrated $p$ value less than 0.2 in the bivariate analysis were incorporated into multiple logistic regressions model for further analysis and $p$-values less than 0.05 indicated as statistically significance.

\section{Ethical issues}

Ethical clearance was obtained from School of Public Health, research ethical review committee of Addis Ababa University (AAU). Formal letter of support was written to Ambo town health office by School of Public Health, AAU. To participate in this study, a written consent was obtained from respondents above 18 years old and from the parents/guardians for those whose age less than 18 years old females; after informing the objectives of the study; the right to participate and not participate or to terminate the interview at any time was fully explained before data collection. Respondents were free to decline participation, and we made it sure that if they decide so far administered data will not be stored. Confidentiality was maintained by not mentioning their name on the questionnaire. 


\section{Results}

\section{Socio-demographic variables}

Three hundred fifty one (55.3\%) were found in age group of 15-19 years. The mean age was 16.6 years $(\mathrm{SD}=2.3$, age range: 10-24). Three hundred ninety seven $(62.7 \%)$ were Oromo in ethnicity. Orthodox Christian followers (51.9\%) were taken the lead in the study area. Regarding marital status of the respondents, $80.0 \%$ were singles or unmarried. Two hundred forty seven $(38.9 \%)$ were preparatory and TEVT and $74.8 \%$ were attended in school at the time of the survey (Table 1).

\section{Sexual history}

Three hundred seventeen (49.9\%) of the surveyed youths have ever had sex. The Mean \& median age of sexual initiation in this study were 16.6 years $(\mathrm{SD}=2.3)$ (Range $10-24$ years). Three-fifth (60\%) of the respondents was initiated sex before age of 18 years. The main reasons for engaging in first time sex were passionate love (30.7\%), any

Table 1 Socio-demographic characteristics of the respondents in Ambo, April 2013

\begin{tabular}{|c|c|c|}
\hline Variables & Number & Percent (\%) \\
\hline \multicolumn{3}{|l|}{ Age group (years) } \\
\hline $15-19$ & 351 & 55.3 \\
\hline $20-24$ & 284 & 44.7 \\
\hline \multicolumn{3}{|l|}{ Ethnicity } \\
\hline Oromo & 397 & 62.5 \\
\hline Amhara & 144 & 22.7 \\
\hline Tigre & 58 & 9.1 \\
\hline Others & 36 & 5.7 \\
\hline \multicolumn{3}{|l|}{ Religion } \\
\hline Orthodox & 330 & 51.9 \\
\hline Protestant & 193 & 30.4 \\
\hline Muslim & 65 & 10.2 \\
\hline Catholic & 32 & 5.0 \\
\hline Others & 15 & 2.4 \\
\hline \multicolumn{3}{|l|}{ Marital status } \\
\hline Married & 127 & 20.0 \\
\hline Unmarried & 508 & 80.0 \\
\hline \multicolumn{3}{|l|}{ Education } \\
\hline Primary school 1-8 & 112 & 17.6 \\
\hline Secondary school 9-10 & 222 & 35.0 \\
\hline Preparatory \& TEVT & 247 & 38.9 \\
\hline College \& Above & 54 & 8.5 \\
\hline \multicolumn{3}{|l|}{ Currently in school } \\
\hline Yes & 475 & 74.8 \\
\hline No & 160 & 25.2 \\
\hline
\end{tabular}

Table 2 Reasons to start sex by respondents in Ambo town; Ethiopia; 2013

\begin{tabular}{lll}
\hline Variables & Number & Percent (\%) \\
\hline Passionate love & 195 & 30.7 \\
Any substance use & 163 & 25.7 \\
Feeling maturity & 124 & 18.67 \\
Desire for marriage & 80 & 12.6 \\
Peer pressure & 39 & 5.87 \\
Rape & 38 & 5.72 \\
Receiving gift & 13 & 1.96 \\
Pornographic material & 12 & 1.9 \\
\hline
\end{tabular}

substance use (25.7\%), feeling maturity (18.7) and followed by desire for marriage (12.6\%) (Table 2 ).

\section{Peer influence}

The role of peer pressure on sexual debut was observed in this study. Two hundred thirty one (36.4\%) were responded that they had ever been encouraged by their friends to take part in sexual activities. Furthermore, $24.9 \%$ of respondents had been encountered pressure from their peers to have sexual intercourse more frequently (Table 3 ).

Table 3 Peer pressure and non-sexual related behaviors regarding sexual debut among female youths in Ambo town; Ethiopia April 2013

\begin{tabular}{lcc}
\hline Variables & Frequency & Percent \\
\hline Had sex & 317 & 49.9 \\
Yes & 318 & 50.1 \\
No & & \\
Peer pressure & 231 & 36.4 \\
Yes & 404 & 63.6 \\
No & 158 & \\
Peers influence to have sexual intercourse & 24.9 \\
Frequently & 243 & 38.3 \\
Occasionally & 234 & 36.8 \\
Not at all & & \\
Used any substance & 193 & 30.4 \\
Yes & 442 & 69.6 \\
No & & \\
Drunk alcohol & 299 & 47.1 \\
Yes & 336 & 53.9 \\
No & & 36.8 \\
Viewed Pornographic material & & 64.2 \\
Yes & 234 & \\
No & 401 & \\
\hline
\end{tabular}




\section{Behaviors of non sexual related risks}

One hundred ninety three (30.4\%) have used substances. The most abused substance was Khat (94.6\%).respondents were also practiced other non sexual risk behaviors such as drinking alcohol 299 (47.1\%), viewing pornographic materials 234 (36.2\%).

\section{Factors associated with sexual debut}

Educational status, peer influence, age, any substance use, being in school, drinking alcohol and viewed pornographic materials had showed statistically significant ( $p$-value $<0.05)$ association with sexual debut in bivariate logistic regression analyses. After controlling for potential confounding factors, logistic regression analysis showed that, those young women who chewed Khat were found to 1.3 times more likely to already have been engaged to sexual intercourse than those who did not consume Khat"). Furthermore, those who drank alcohol and viewing pornographic materials were found to 2.2 times and 2.3 times more likely to initiate sexual activities respectively (Table 4).

\section{Discussion}

We have found that $49.9 \%$ have ever had sex. The finding is similar to other studies conducted in different countries on sexual behavior among female youths. The mean age at first sexual debut was $16.6(+\mathrm{SD}=2.3)$ years and this is comparable with other previous studies in Ethiopia $[2,11]$. However, the mean year of sexual debut in this study is higher than previous studies conducted in Ethiopia, Ethiopian Demographic Health Survey (EDHS) 2016 (16.6 years), in Dessie, north east Ethiopia (16.8 years), in Kolladiba, north west Ethiopia (15 years), in Gojam, north west Ethiopia (13.5 years) and in Butajira, southern Ethiopia (16 years) [2, 12-14]. The difference might be due to the decrease in early marriage [15] and because of the recently endorsed family law [16].

We have found that 231 (36.4\%) had ever been encouraged by their friends to practice sexual activities. Furthermore, $24.9 \%$ of respondents had been encountered pressure from their peers to have sexual intercourse regularly. Furthermore, logistic regression analysis also revealed that respondents' external pressure lead to first

Table 4 Factors contributing to sexual initiation among female youths, in Ambo town, April 2013, Ethiopia

\begin{tabular}{|c|c|c|c|c|}
\hline \multirow[t]{2}{*}{ Characteristics } & \multicolumn{2}{|c|}{ Sexual Initiation } & \multirow[t]{2}{*}{ Crude OR (95\% Cl) } & \multirow[t]{2}{*}{ Adjusted OR (95\% Cl) } \\
\hline & Yes & No & & \\
\hline \multicolumn{5}{|l|}{ Age group (years) } \\
\hline $15-19$ & $104(33.7)$ & $236(72.4)$ & 1.00 & 1.00 \\
\hline $20-24$ & $205(66.3)$ & $90(27.6)$ & $5.17(3.68,7.25)$ & $2.75(1.74,4.34)$ \\
\hline \multicolumn{5}{|l|}{ Education } \\
\hline Primary school 1-8 & $77(24.9)$ & $105(32.2)$ & $0.15(0.06,0.31)$ & $0.25(0.10,0.62)$ \\
\hline Secondary school 9-10 & $94(30.4)$ & $128(39.3)$ & $0.14(0.06,0.31)$ & $0.20(0.08,0.48)$ \\
\hline Preparatory \& TEVT & $93(30.1)$ & $84(25.8)$ & $0.22(0.10,0.48)$ & $0.30(0.12,0.73)$ \\
\hline College \& Above & $45(14.6)$ & $9(2.8)$ & 1.00 & 1.00 \\
\hline \multicolumn{5}{|l|}{ Currently in school } \\
\hline Yes & $151(48.9)$ & $284(87.1)$ & $0.14(0.09,0.21)$ & $0.19(0.11,0.33)$ \\
\hline No & $158(51.1)$ & $42(12.9)$ & 1.00 & 1.00 \\
\hline \multicolumn{5}{|l|}{ Peer influence } \\
\hline Yes & $163(52.8)$ & $86(26.4)$ & $2.92(2.09,4.08)$ & $3.20(2.08,4.94)$ \\
\hline No & $146(47.2)$ & $240(73.6)$ & 1.00 & 1.00 \\
\hline \multicolumn{5}{|l|}{ Used any substances } \\
\hline Yes & $98(31.7)$ & $73(22.4)$ & $10.1(3.94,25.89)$ & $1.30(0.83,2.06)$ \\
\hline No & $211(68.3)$ & $253(77.6)$ & 1.00 & 1.00 \\
\hline \multicolumn{5}{|l|}{ Drank alcohol } \\
\hline Yes & $180(58.3)$ & $109(33.4)$ & $8.26(5.25,13.0)$ & $2.17(1.43,3.28)$ \\
\hline No & $129(41.7)$ & $217(66.6)$ & 1.00 & 1.00 \\
\hline \multicolumn{5}{|c|}{ Viewed pornographic materials } \\
\hline Yes & $144(46.6)$ & $73(22.4)$ & $3.46(2.43,4.92)$ & $2.27(1.43,3.61)$ \\
\hline No & $165(53.4)$ & $253(77.6)$ & 1.00 & 1.00 \\
\hline
\end{tabular}

Significance: $p<0.05 ., 1.00$ : Reference category 
sex, which is similar with a cross-sectional and the National Longitudinal Study of Adolescent Health conducted in three Developing Countries, University of Minnesota, Minneapolis and Penn Institute for Economic Research [17], which revealed that peer norms have a substantial effect on the timing of sexual initiation for both boys and girls. According to Social-psychological theories of health behavior, adolescents' sexual behaviors are influenced by the sexual attitudes and behaviors of their friends [18]. As different studies demonstrated, adolescents who are highly involved with their friends may find themselves in social contexts that encourage early dating and entry into romantic relationships, which have been linked to earlier sexual initiation.

Around $30 \%$ of the respondents were used any substance to make feel high; mainly of Khat (94.6\%), drinking alcohol $47.1 \%$ and viewing pornographic materials $36.8 \%$. Illegal trading drug and misuse are now becoming more frequent in the country [19].

Our study finding demonstrated that substance users were found to be initiate sexual intercourse earlier than non-users, which is comparable with a cross-sectional study conducted in North East Ethiopia and nine European cities [2, 20].

A multivariate logistic regression analyses demonstrated that alcohol drinkers were twice at higher risk to initiate sexual intercourse than non-drinkers, which is similar with other findings [15, 21].

Viewing Pornographic material which typically followed by alcoholic drinks mentioned as a major contributing factor to sexual initiation in the study area. Pornographic material viewers were found to be twice more likely at higher risk to initiate sex, which is almost similar with a cross-sectional study done in Dessie, north east Ethiopia, revealed that the increased openness to Western culture has resulted in the invasion of pornographic videos, books, and magazines, whose consumers are mostly young people [2] and The National Longitudinal Study of Adolescent Health also supported this finding [22].

\section{Conclusions}

The proportion of sexual debut was high; peer influences have a substantial effect on the timing of sexual debut for girls. Non sexual risky behaviors such as viewing pornographic materials, using any substances (such as Khat) and drinking alcohol especially at earlier age are independent predictors of sexual debut. Therefore, strengthening the norm of virginity, which delays sexual intercourse, should be advocated. There is need to target building life skills, establishing and strengthening youth friendly clubs, particularly for females, in making informed decisions about sexuality issues to reduce youth reproductive health problems. This intervention will certainly include provision of youth-friendly services by local government, non-governmental and communitybased organizations.

\section{Acknowledgments}

We would like to acknowledge Addis Ababa University for granting opportunity to undertake this study. We are also thankful to the respondents who participated in this study.

\section{Funding}

The project was funded by UNFPA through the school of School of Public health Addis Ababa University. The organization has no role in the design, collection, analysis and interpretation of data and in writing the manuscript.

\section{Availability of data and materials}

The datasets generated and/or analysed during the current study are available in the Addis Ababa University repository, WEB LINK TO DATASETS: http://etd.aau.edu.et/bitstream/123456789/6222/1/Digafe\%20new.pdf.

\section{Authors' contributions}

DTN was a principal investigator, was involved in proposal writing, designing the methodology, questionnaire, recruitment and training of data collectors and supervisors, analysis, write-up and in all stages of the project implementation including in development of the manuscript. AS involved in proposal development, designing the methodology, questionnaire design, and involved in final approval of the paper. SF and MTS involved in development of the manuscript. All authors read and approved the final manuscript.

\section{Ethics approval and consent to participate}

The School of Public Health, Addis Ababa University (AAU), research ethical review committee was approved the Ethical clearance. An official letter of support was obtained from Addis Ababa University. Then, a written consent obtained from respondents above 18 years old and from the parents/ guardians for those whose age less than 18 years old females and the information were kept confidential.

\section{Competing interests}

The authors declare that they have no competing interests.

\section{Publisher's Note}

Springer Nature remains neutral with regard to jurisdictional claims in published maps and institutional affiliations.

\section{Author details}

${ }^{1}$ Department of Public Health, College of Medicine \& Health Sciences, Ambo University, Ambo, Ethiopia. ${ }^{2}$ School of Public Health Addis Ababa University, Addis Ababa, Ethiopia. ${ }^{3}$ Department of Public Health, College of Health Science, Arsi University, Assela, Ethiopia.

Received: 4 March 2016 Accepted: 11 May 2018

Published online: 30 May 2018

References

1. Fhi U. Youth Net Assessment Team: Assessment of youth reproductive health programs in Ethiopia, A. Ethiopia: United States Agency for International Development; 2004

2. Mazengia F, Worku A. Age at sexual initiation and factors associated with it among youths in north East Ethiopia. Ethiop J Heal Dev. 2009;23(2):34-48.

3. Miangotar $Y$, Thomas $L$. Association between age at first sexual relation and some indicators of sexual behavior among adolescents. Afr J Reprod Health. 2012;Spec. Ed. 16(2):21-5.

4. Central Statistical Agency (Ethiopia) and ORC Macro. Ethiopia demographic and health survey 2011. Addis Ababa: Central Statistical Agency: ICF International Calverton, Maryland, USA; 2012.

5. Taffa N, Sundby J, Bjune G. Reproductive health perceptions, belief and sexual risk taking among youth in Addis Ababa. Patient Educ Couns. 2003:49:165-7.

6. Barbara S, Monica J, Ann K. The changing context of sexual initiation in Sub-Saharan Africa. Can be available online at www.popcouncil.org/ publications/wp/prd/rdwplist.html, 2005.

7. Tilahun M, Ayele $G$. Factors associated with age at first sexual initiation among youths in Gamo-Gofa, South West Ethiopia: a cross sectional study. BMC Public Health. 2013;13:622.

8. Seme A, Wirtu D. Premarital sexual practice among school adolescents in Nekemte Town, East Wollega. Ethiop J Health Dev. 2008;22(2):167. 
9. HIV/AIDS Prevention and control Office (HAPCO). Behavioral surveillance survey in Ethiopia; 2000. p. 14-25.

10. Yemane B, et al. HIV/AIDS in Ethiopia -an epidemiological synthesis. Washington, DC: The World Bank; 2008. p. 27-109. Also available at www.worldbank.org/AIDS.

11. Zelalem F. Casual sex-debuts among female adolescents in Addis Ababa, Ethiopia. Ethiop J Heal Dev. 2001;15(2):9-40.

12. Mitike M, Yemane B, Bernt L. Traditional values of virginity and sexual behavior in rural Ethiopian youth: results from a cross-sectional study. BMC Public Health. 2008;8:9. 17-32.

13. Ismail S, Bitsuamlak H, Alemu K. High risk sexual behaviors for STD/HIV, pregnancies and contraception among high school students in a rural town, North Western Ethiopia. Ethiop J Health Dev. 1997;11(1):29-36.

14. Alemayehu S, Mesganaw F, Alemayehu W. Reproductive health needs of out-of-school adolescents: across-sectional comparative study of rural and urban areas in Northwest Ethiopia. Ethiop J Health Dev. 2006;20(1):10-7.

15. Campbell EK. A note on alcohol consumption and sexual behavior of youths in Botswana. African Sociol Rev. 2003;7(1):146-61.

16. Federal Negarit Gazetta of the Federal Democratic Republic of Ethiopia. The revised family code, Federal Negarit Gazetta, Extra ordinary issue no. 1/2000 Addis Ababa: The Revised Family Code Proclamation No. 213/2000; 2000. 4thDay of July.

17. Richards-Shubiky S. Peer effects in sexual initiation: separating demand and supply mechanisms. Penn Institute for Economic Research. Department of Economics, Lehigh University. 2015;6:663-02.

18. Ensminger ME. Adolescent sexual behavior as it relates to other transition behaviors in youth. In: Hofferth SL, Hayes CD, editors. National Research Council (US) panel on Adolescent pregnancy and childbearing. Washington (DC): National Academies Press (US); 1987.

19. Kebede $D$, et al. Khat and alcohol use and risky sexual behavior among in-school and out-of-school youth in Ethiopia. BMC Public Health. 2005;5:109. http://www.biomedcentral.com/1471-2458/5/109.

20. Bellis MA, Hughes K, Calafat A, Juan M, Ramon A, Rodriguez JA, Mendes F, Schnitzer S, Phillips-Howard P. Sexual uses of alcohol and drugs and the associated health risks: a cross sectional study of young people in nine European cities. BMC Public Health. 2008;8:155. available at: http://www.biomedcentral.com/1471-2458/8/155.

21. Malaju MT, Asale GA. Association of Khat and alcohol use with HIV infection and age at first sexual initiation among youths visiting HIV testing and counseling centers in Gamo-Gofa Zone, South West Ethiopia. BMC Int Health Hum Rights. 2013;13:10. available at: http://www.biomedcentral.com/ 1472-698X/13/10)

22. Ashby SL, Arcari CM, Bruce Edmonson M. Television viewing and risk of sexual initiation by young adolescents. Am Med Assoc. 2006;160:375-80

\section{Ready to submit your research? Choose BMC and benefit from:}

- fast, convenient online submission

- thorough peer review by experienced researchers in your field

- rapid publication on acceptance

- support for research data, including large and complex data types

- gold Open Access which fosters wider collaboration and increased citations

- maximum visibility for your research: over $100 \mathrm{M}$ website views per year

At BMC, research is always in progress.

Learn more biomedcentral.com/submissions 